\title{
MENTAL DISEASES.
}

\author{
UNDER THE CHARGE OF
}

\section{JAMES MIDDLEMASS, M.D.}

\section{Tests Applied to Spinal Fluid in Psychiatry.}

Drs. Weston, Darling, and Newcomb report the results of a series of tests of the cerebro-spinal fluid in 198 cases of mental disease (Amer. Journ. of Insan., April 1915, p. 773). Besides the Wassermann and Noguchi tests the number of cells was counted, the globulin content estimated, and the Zsigmondi colloidal gold test was applied. The last is comparatively a new method, and it is of interest to compare the results found by it with the older and better-known ones. The test depends on the power of proteins when in excess to precipitate gold from a specially prepared colloidal solution in sodium chloride. The technique is elaborate, and the greatest care is required in the preparation of the reagents employed. Lange in 1912 ascertained that it is a sensitive test of the presence of syphilitic affections of the cerebrospinal system, and since his time various other researches have been conducted on the same lines. The present report describes the technique and gives the results of over 200 tests. Of the cases investigated 3 were of syphilitic cerebro-spinal disease, 34 were general paralytics, and the rest various other forms of mental disease. The results of each test are given. The conclusions at which the authors arrived were as follows:-

1. In cases diagnosed as cerebro-spinal syphilis the Wassermann reaction upon the spinal fluid was always positive, and the colloidal gold test showed a reaction.

2. In general paralysis the gold test was always found positive in cases where the spinal fluid showed a similar reaction to the Wassermann test, in addition to which there is one instance in which the latter was negative and the former positive.

3. In dementia præcox, manic-depressive insanity, arteriosclerotic dementia, and epilepsy there were no positive Wassermann reactions, and likewise no typical response to the gold solution. The latter reagent, however, did furnish 8 cases showing a minor reaction.

4. In the unclassified psychoses the gold and Wassermann tests ran a parallel course except in one case. In this case also the former gave a minor reaction, whilst the latter was negative. This was clinically a possible case of paresis.

5. From this investigation the conclusion is drawn that the gold reaction forms a useful adjuvant to the Wassermann test, is apparently as reliable, and in some instances has appeared to anticipate the latter. 


\section{The Catatonic Type of Dementia Pracox.}

In this paper Dr. Dunlop Robertson advances a number of propositions which lead him to the conclusion that this type of dementia præcox is due to an adrenal intoxication (Journ. of Ment. Sci., July 1915, p. 392). He quotes an extensive array of authors who lead him to this view, but it must be said that the most of these opinions are at the best too speculative to carry any great burden of proof. He is able to refer to only a single experiment of his own which is at all confirmatory of his hypothesis. The blood of two patients-one catatonic, the other not-was taken, allowed to coagulate, and equal quantities of each were tested with a few drops of a saturated solution of potas. bichrom. In the former a deep coloration was produced, in the other not. It is not stated that this test is specific for adrenalin; and as it is known that blood-serum is a most complex mixture of organic and inorganic substances, the greatest care is necessary in interpreting the significance of a single reaction. In this particular case it is interesting to note that the cerebro-spinal fluid did not react to the same test. One would imagine that it would be probable, but not of course certain, that if one reacted to the test the other would also. Another point which the author does not seem to dispose of satisfactorily, though he refers to it, is the low blood-pressure usually found in these cases. If adrenalin is present in excess in the blood one would expect the pressure to be raised at least in the early stages of the illness. Such has not proved to be the case, however. It may possibly be, as the author suggests, that a great excess of adrenalin may have a paralysing and not a stimulating effect. Such contradictory results are known in connection with other organic substances. It would, however, appear to be capable of definite experimental proof. The views put forward by Dr. Robertson may ultimately prove to be correct, but much more observation is required before they can be accepted as proved.

\section{Thalamic Guiosis in Dementia Precox.}

In this paper (Amer. Journ. of Insan., July 1915, p. 103) Dr. Mary E. Morse gives the results of a pathological investigation of the thalamus in a series of cases of dementia præcox. She chose this part of the nervous system because it has a close relation with sensory impulses passing to the cortex, with the cerebellum, and with the sympathetic system. A short account is given of what is known of the development and minute anatomy of the thalamus. The cases investigated by the authoress were from the Worcester State Hospital, and included 10 cases of dementia præcox who died at an age when arteriosclerotic and senile changes could be excluded, and were uncomplicated by other recognised nervous lesions. Brief clinical abstracts of these cases are reported, and the pathological findings as well. The methods 
of examination and the positions from which sections were taken are also described. Eleven control cases were examined in an exactly similar way, and the results of the examination of these are given as well.

As a general result of the whole investigation Dr. Morse states that the distinctive change in the thalamus in dementia præcox is a gliosis. Degenerative changes in the nerve cells and perivascular accumulation, when present in the thalamus, were also found in the cerebral cortex, except in a few cases. In these perivascular infiltration was confined to the thalamus. This thalamic gliosis occurs more frequently in dementia præcox cases than in the case of other psychoses who die at about the same ages. A marked gliosis may occur in the thalamus in dementia præcox at a period when there is little gliosis in other parts of the nervous system. In none of the cases was the gliosis strictly limited to the thalamus, but in the majority of those in which it was present there it exceeded that found elsewhere. The areas most frequently involved are the median nuclei and the pulvinar. The age at death and the duration of the psychosis have a marked influence on the occurrence of gliosis. Those in which it was absent or slight ( 4 cases) were under 40 years of age, and the psychosis had not existed more than a year. When the patient was advanced in years and the disease was of long duration ( 2 cases) the gliosis tended to be very marked both in the thalamus and in other parts of the nervous system. In the intermediate group (4 cases) the disease occurred in the fifth and sixth decades, and it had been in existence from three to five years. The interpretation of the lesion and its relation, if any, to the symptoms are problematical.

\section{Thymus and Pituitary in Dementia Precox.}

Drs. Ludlum and Corson White have investigated the Abderhalden reaction to testicle and pancreas in cases of dementia præcox, and found it positive in certain of them (Amer. Journ. of Insan., April 1915, p. 733). These cases presented certain physiological characteristics, such as leukopenia, increased blood-pressure, feeble and rapid pulse, exaggerated reflexes, tremor of tongue and extremities, etc. In seeking an explanation of these apparently correlated symptoms they were led to associate them with the condition of the thymus, partly as the result of investigation of the Abderhalden reaction in two thymectomised dogs, partly from a study of the views of various authors on the physiology of the thymus. On this supposition they treated six cases with thymus gland extract, and three recovered satisfactorily.

In certain other cases giving no Abderhalden reaction they found another group having a different aggregate of symptoms. These had a very low blood-pressure, which fell on standing (contrary to the general rule); the pulse was slow; the deep reflexes were diminished, 
sometimes absent; the temperature was subnormal, sometimes $2^{\circ}$; and the testicles were small. Reasoning again, from the known symptoms produced by deficiency of secretion of one of the glands of internal secretion, they concluded that the above were due to dyspituitarism. Under treatment with pituitary gland most of these cases showed improvement. In still another series of cases the symptoms generally seemed to point to hyperpituitarism. These were treated with testicular extract or Brown-Séquard fluid, and in them also there was a rapid subsidence of the mental symptoms.

In the authors' opinion the study of the glands of internal secretion should be further pursued as being likely to lead to a better knowledge of dementia præcox.

\section{Certification under the Mental Deficiency Act.}

A short but interesting paper by Dr. Potts, Medical Officer to the Birmingham Committee for the Care of the Mentally Defective, will repay perusal by those upon whom the recent Act has placed the responsibility of examining mental defectives (Birm. Med. Rev., May 1915 , p. 129). Dr. Potts is specially qualified to speak with authority on this subject, as he was for ten years chairman of the Birmingham AfterCare Committee, which dealt with many mental defectives voluntarily before the Act made this a duty.

The first part of the paper gives a short account of the persons brought under the Act, and need not be further referred to. The second gives many useful hints in the examination of patients with a view to certification. The main evidence of defect must of course be based on facts ascertained by the medical man at his own examination of the patient. It is well to have a systematic method of ascertaining these facts, and they are best arranged under the headings of appearance, conduct, and conversation. Marked stigmata of degeneration, especially if there are several, are permissible under the first. As to conduct, it is often the only basis of the certificate. This should be closely observed during the whole of the examination. It assists materially in the estimation of intelligence, which, however, comes chiefly under the third heading. Certain special tests are mentioned as ready examples of simple methods of ascertaining the intellectual development of the patient, and these of course must vary with age. Samples are also given of statements in actual certificates which illustrate the sort of facts which have complied with the requirements of the Act and have stood the test of practical experience. A caution is uttered as to the necessity of eliminating the effects of physical conditions which influence the results of the examination but are not evidences of mental defect. Such are slight deafness, physical illness, hunger, etc. It is highly necessary to keep these in mind when persons belonging to classes in which these conditions are common are dealt with. It will be seen that the paper well repays perusal. 